\title{
Comment on "Ultrasound-guided hydrodilatation for adhesive capsulitis of the hip is a safe and effective treatment"
}

\author{
Shuaijie Jin ${ }^{1}$ Peijian Tong ${ }^{2}$ \\ Received: 1 March 2022 / Accepted: 2 March 2022 / Published online: 7 March 2022 \\ (c) The Author(s) under exclusive licence to SICOT aisbl 2022
}

\section{Dear Editor,}

With great interest, we read the article "Ultrasound-guided hydrodilatation for adhesive capsulitis of the hip is a safe and effective treatment [1]" by Byung-Ho Yoon et al. Many thanks to the authors for their contribution in studying the use of ultrasound-guided hydrodilatation for adhesive capsulitis of the hip. But I have a very important question that I would like to discuss with the author.

The authors conclude that US-guided hip injection with hydrodilatation can be recommended as a safe and effective way of obtaining symptom relief in patients with $\mathrm{ACH}$. This trial was prospective, but it is unfortunate that the authors only included 84 patients in the trial and did not divide the patients into an operative group and a blank control group. $\mathrm{AC}$ is a self-limiting disease with the potential for selfrecovery during its natural course of progression. Because the results of this trial lacked comparison with a blank control group, I do not believe that these results support the authors' conclusions.

Until now, the article does not have clear evidence what explains the improvement of adhesive capsulitis after hydrodilatation, whether it is related to capsule distension with hydrodilatation, corticosteroid, or the local anesthetic effect or the combination. Therefore, further longitudinal controlled randomized trials are needed to explain the underlying mechanisms.

This comment refers to the article available online at https://doi. org/10.1007/s00264-020-04909-y.

Peijian Tong

tongpeijian@163.com

1 The First Clinical Medical College, Zhejiang Chinese

Medical University, Hangzhou 310006, China

2 The First Affiliated Hospital of Zhejiang, Chinese

Medical University, 54 Youdian RoadZhejiang Province,

Hangzhou 310053, China
Author contribution Shuaijie Jin wrote and revised the manuscript. Peijian Tong contributed to supervision of the manuscript. All authors have the manuscript and agree with submission.

Data availability All data generated or analyzed during this study are included in this published article.

\section{Declarations}

Ethics approval Not applicable.

Consent to participate Not applicable.

Consent for publication The authors declare that they agree to publish.

Competing interests The authors declare no competing interests.

\section{Reference}

1. Yoon BH, Shim JC, Lee M, Oh HK, Sung YB, Choo SK (2021) Ultrasound-guided hydrodilatation for adhesive capsulitis of the hip is a safe and effective treatment. Int Orthop 45(6):1455-1461. https://doi.org/10.1007/s00264-020-04909-y

Publisher's Note Springer Nature remains neutral with regard to jurisdictional claims in published maps and institutional affiliations. 